Himalayan Biodiversity 6: 52-57, 2018

\title{
AGRO-MORPHOLOGICAL DIVERSITY (QUANTITATIVE TRAITS) OF RICE (ORYZA SATIVA L.) CULTIVATED IN BAGLUNG DISTRICT, NEPAL
}

\author{
Hom Nath Pathak \\ Department of Botany, \\ PN Campus, Pokhara, Nepal \\ Email: homnpathak@gmail.com
}

\begin{abstract}
Agro-morphological traits are the features of cultivated rice i.e. Oryza sativa L. Rice landraces differ from the other landrace in morphological features such as grain weight, culm number, and height of the plant. Nineteen different landraces of cultivated rice from Paiyunpata village, Baglung were studied and their quantitative characters were measured. The most varied landraces in morphological characters (Khate, Rato, Nepale, Anadi etc. i.e. species far from quadrantsin PCA) are suggested for crop improvement. Findings from this research could be helpful for germplasm conservation.
\end{abstract}

Key words: Agromorphology, germplasm conservation, landraces,

\section{INTRODUCTION}

Crop diversity is affected by natural and manual selection of agro-morphological traits and management (Yadav et al 2001). Different varieties of rice are cultivated based on their suitability and adaptability to the local environment. Exploration of these local varieties and theirhabitat is essential for theirconservation. The varietal improvement/selection process is replacing indigenous landraces, resulting in the loss of genetic resources. Genetic erosion is higher in rice than in any other crops (Adhikari et al, 1994).

The morphological characteristics of these different rice varieties may help to recognize these landraces from other landraces. Therefore, morphological characteristics and their variability are studied for their identities in villages, country and abroad. High level of genetic diversity is expected among landraces and the information may be helpful to the plant breeders to choose the right parent for crop improvement (Roy and Sharma, 2014). These various morphological characters include the height of the tiller, internodal length, presence of awn, apiculus, number of tillers, number of grains per inflorescence (Anonymous, 2011). A preliminary study made by Pathak and Paudyal (2008) in Paiyunpata village of Baglung district has revealed the cultivation of 23 landraces of rice. Based on such finding, the proposed study intends to study agro-morphological characters of these landraces under traditional cultivation method, which would be beneficial to understand the relative importance of each landrace in varietals' improvement programs.

\section{MATERIALS AND METHODS}

\section{Study area}

There were 1300 households in Paiyunpata village. The total population was 5200 there (CBS, 2013). It is ward number 13 of the Baglung Municipality, now. The main occupation of the people is farming. The main food crops of the area are rice, wheat, maize and millet. Animal husbandry is the common agricultural practice of the inhabitants. The area lies in the sub- 
tropical region with Schima-Castanopsis forest as major natural vegetation. (Chaudhary, 1984). About two third of the land is under rice cultivation in the study area. Almost all rice fields are irrigated, very few cases are rain fed. The cultivation system is based on subsistence farming. Commercialization is very rare. Most of the farmers cultivate local landraces of rice.

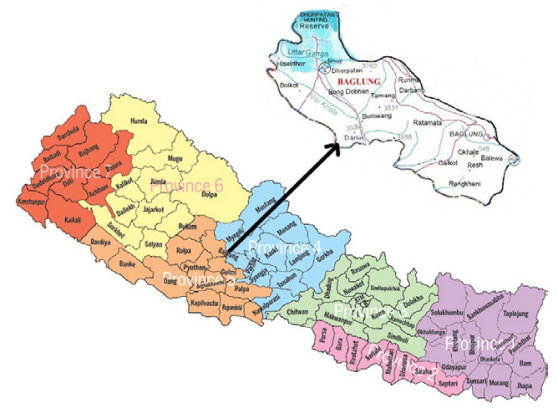

Fig. 1: Map of Nepal with Baglung District (source internet).

\section{Study design}

Rice field for seedbed was ploughed once during winter. It was ploughed and the soil was made finer. Pebbles, if any, were removed and made ready for seed bed preparation. Finally, the field was ploughed mixing compost fertilizers sufficiently. Nineteen plots were prepared for the nineteen landraces (Tangale, Nepale, Resali, Anadi, Jarneli, Bhattte, Ratopatle, Aanga,
Rause, Khate, Gola, Sinjali, Gauriya, Ekle, Kathe jhinuwa, Kodegudura, Ramani, Dauthe and Bhainsegudura ) of rice. Seeds were sown and mulched with soil from the top to prevent the picking up of the rice grains by birds and run away by water.

Rice field was prepared on farmers' way. Plots were prepared and every rice seedling was planted in $20 \times 20 \mathrm{~cm}$ apart one another (Anonymous, 2011). In the rice field, early ripening varieties and late varieties were planted from north to south in the same field as follows Tangale, Nepale, Resali, Anadi, Jarneli, Bhattte, Ratopatle, Aanga, Rause, Khate, Gola, Sinjali, Gauriya, Ekle, Kathe jhinuwa, Kodegudura, Ramani, Dauthe and Bhainsegudura.

Rice descriptor was used to collect data for quantitative and qualitative characters. The quantitative characters include the number of tiller per hill, plant height, panicle, 100 grain weight, culm length, number of culms, grain length and width etc.

To obtain data and agro-morphological diversity among the landraces from the study area, IPGRI rice descriptor (Annonymous, 2011) was followed. About ten different characteristics were observed. To analyze data, cluster analysis and PCA were performed using MINITAB 14, multivariate analysis software.

\section{RESULT AND DISCUSSION}

Table 1. Qualitative characters of rice landraces.

\begin{tabular}{cccccccccccc}
\hline $\begin{array}{c}\mathrm{S} \\
\mathrm{N}\end{array}$ & Name & $\begin{array}{c}\text { Leaf } \\
\text { length } \\
(\mathrm{cm})\end{array}$ & $\begin{array}{c}\text { Leaf } \\
\text { width } \\
(\mathrm{cm})\end{array}$ & $\begin{array}{c}\text { Ligule } \\
\text { length } \\
(\mathrm{cm})\end{array}$ & $\begin{array}{c}\text { Days to } \\
\text { heading } \\
(\text { Approx })\end{array}$ & $\begin{array}{c}\text { Culm } \\
\text { length } \\
(\mathrm{cm})\end{array}$ & $\begin{array}{c}\text { Culm } \\
\text { number }\end{array}$ & $\begin{array}{c}\text { Panicle } \\
\text { length } \\
(\mathrm{cm})\end{array}$ & $\begin{array}{c}\text { 100 Grain } \\
\text { weight }(\mathrm{g})\end{array}$ & $\begin{array}{c}\text { Grain } \\
\text { length } \\
(\mathrm{cm})\end{array}$ & $\begin{array}{c}\text { Grain } \\
\text { width } \\
(\mathrm{cm})\end{array}$ \\
\hline 1 & Tangale & 50 & 1 & 0.7 & 2.5 & 140 & 3 & 28 & 0.9 & 0.7 & 0.4 \\
2 & Nepale & 52 & 0.8 & 5.3 & 2.25 & 108 & 4 & 18 & 0.96 & 0.8 & 0.4 \\
3 & Resali & 49 & 0.9 & 2 & 2.5 & 170 & 3 & 21 & 0.38 & 0.7 & 0.2 \\
4 & Bhatte & 41 & 0.9 & 0.7 & 2.5 & 122 & 3 & 20 & 0.35 & 0.7 & 0.4 \\
5 & Rato & 50 & 1 & 0.8 & 2.5 & 167 & 4 & 30 & 0.69 & 0.7 & 0.4 \\
6 & Aanga & 42 & 1 & 0.9 & 2.5 & 120 & 6 & 22 & 0.31 & 0.9 & 0.3 \\
7 & Rause & 22 & 0.4 & 0.9 & 2.25 & 122 & 7 & 20 & 0.45 & 0.7 & 0.4
\end{tabular}




\begin{tabular}{cccccccccccc}
8 & Khate & 18 & 0.8 & 0.6 & 2.5 & 160 & 4 & 24 & 0.45 & 0.6 & 0.3 \\
9 & Daunthe & 60 & 1 & 0.8 & 2.5 & 150 & 4 & 27 & 0.63 & 0.6 & 0.4 \\
10 & Anadi & 57 & 1.2 & 3 & 3.2 & 153 & 3 & 26 & 0.65 & 1 & 0.4 \\
11 & Jarneli & 49 & 1.2 & 2.5 & 3.2 & 115 & 4 & 24 & 0.28 & 0.8 & 0.3 \\
12 & Kodegudura & 46 & 1 & 2.2 & 3.2 & 144 & 4 & 29 & 0.38 & 0.5 & 0.3 \\
13 & Sinjali & 53 & 1 & 2.5 & 3 & 156 & 3 & 25 & 0.68 & 0.7 & 0.5 \\
14 & Gauriya & 60 & 0.8 & 2 & 3 & 156 & 3 & 24 & 0.45 & 0.8 & 0.4 \\
15 & Ekle & 55 & 0.8 & 1.5 & 3 & 144 & 4 & 30 & 0.4 & 0.7 & 0.3 \\
16 & kathejhinuwa & 52 & 1.2 & 2.2 & 3 & 158 & 4 & 24 & 0.75 & 0.7 & 0.3 \\
17 & Ramani & 55 & 0.9 & 2.4 & 3 & 166 & 3 & 25 & 0.69 & 0.7 & 0.4 \\
18 & Bhainsegudura & 50 & 1.1 & 2.5 & 3.2 & 155 & 3 & 29 & 0.75 & 0.6 & 0.3 \\
19 & Gola & 47 & 1 & 2.7 & 3.2 & 133 & 3 & 23 & 0.85 & 0.6 & 0.3 \\
\hline
\end{tabular}

Highest leaf length was that of Dauthe and Gauriya $(60 \mathrm{~cm})$. Tangale, Rato, Bhainsegudura had leaf length almost equal value i.e. $50 \mathrm{~cm}$. The lowest leaf length value is that of Rause (22 cm).

Leaf width ranges between $0.4 \mathrm{~cm}$ to $1.1 \mathrm{~cm}$. Second widest leaf width was found in Tangale, Rato, Aanga, Dauthe, Kodegudura, Sinjali and Gola i.e. $1 \mathrm{~cm}$. The lowest value was that of Rause. Nepale, Khate, Gauriya and Ekle had the same value of leaf width i.e. $0.8 \mathrm{~cm}$. A similar value of leaf width was determined in Resali, Bhatte and Ramani $(0.9 \mathrm{~cm})$. The greatest leaf width value was in Bhainsegudura i.e. $1.1 \mathrm{~cm}$.

Ligule length was lowest in Khate $(0.6 \mathrm{~cm})$ and highest in Nepale $(5.3 \mathrm{~cm})$. Jarneli, Sinjali and Bhainsegudura had same value i.e. $2.5 \mathrm{~cm}$. Simailarly Rato and Dauthe had same ligule length $(0.8 \mathrm{~cm})$. Kathe jhinuwa and Kodegudura had the same value. Resali and Gauriya had ligule length of $2 \mathrm{~cm}$. The second ligule length was that of Anadi $(3 \mathrm{~cm})$.

The shortest time for heading was found in Nepale and Rause landraces. After them, Tangale, Resali, Bhatte, Rato, Aanga, Khate and Dauthe possessed a shorter period of heading. The longest period of heading was found in Anadi, Jarneli, Kodegudura, Bhaisegudura and
Gola. Besides, Sinjali, Gauriya and Ekle, Kathe jhinuwa and Ramani possessed heading in 3 months after cultivation.

Culm length varied between $108 \mathrm{~cm}$ (Nepale) to $170 \mathrm{~cm}$ (Resali). Rato had $167 \mathrm{~cm}$ and Ramani had $166 \mathrm{~cm}$ culm length.

The greatest value of culm number was found in Rause landrace i.e. 7. Aanga had six culms per plant. The lowest value of culm number was found in Tangale, Resali, Bhatte, Anadi, Sinjali, Gauriya, Ramani, Bhaisegudura and Gola. Remaining other landraces possess four culms per plant. These landraces were Nepale, Rato, Khate, Dauthe, Jarneli, Kodegudura, Ekle and Kathe jhinuwa.

Panicle length value was highest $(30 \mathrm{~cm})$ in Rato and Ekle. The smallest value of panicle length was observed in Bhatte and Rause. A most similar value of panicle length i.e. 24 $\mathrm{cm}$ was in Khate, Jarneli, Gauriya and Kathe jhinuwa. Second largest panicle was found in Bhaisegudura and Kodegudura i.e. $29 \mathrm{~cm}$.

100 grain weight of rice varieties ranged between 0.28 gm (Jarneli) to 0.96 gm (Nepale) at the dry condition.

The grain length varied between $0.5 \mathrm{~cm}$ (Kodegudura) to $1 \mathrm{~cm}$ (Anadi). Grain length; 0.8 $\mathrm{cm}$ was found in Nepale, Jarneli and Gauriya, 
$0.9 \mathrm{~cm}$ length of grain was found in Aanga. Grain length value was $0.7 \mathrm{~cm}$ in most of the landraces i.e. Tangale, Resali, Bhatte, Rato, Rause, Sinjali, Ekle and Ramani. Grain length of $0.6 \mathrm{~cm}$ was observed in Bhaisegudura and Gola.

Grain width was found greatest in Sinjali (0.5 $\mathrm{cm})$ and lowest in Resali $(0.2 \mathrm{~cm})$. Grain width; $0.4 \mathrm{~cm}$ was observed in 9 landraces out of 19 . They were Tangale, Nepale, Bhatte, Rato, Rause, Dauthe, Gauriya and Ramani. Value $0.3 \mathrm{~cm}$ for grain width was obtained in Aanga, Khate, Jarneli, Kodegudura, Ekle, Bhaisegudura and Gola.

\section{Cluster Analysis}

Four clusters were observed when plotted at of 80 $\%$ similarity level. In the cluster analysis for the quantitative traits using the Euclidean distance, three groups were formed by Nascimento et al (2011). The cluster I contains Tangale, Kodegudura, Ekle, Gola, Resali, Ramani, Daunthe, Anadi, Gauriya, Sinjali, Kate jhinuwa and Bhainsegudura. The cluster II includes Khate. The cludster III includes Nepale, Jarneli, Bhatte, Aanga and Rause. Cluster IV includes only landrace Rato. Cluster analysis based on quantitative characters showed great variability among the tested rice accessions in a study by Mau et al. (2017) in Indonesia.

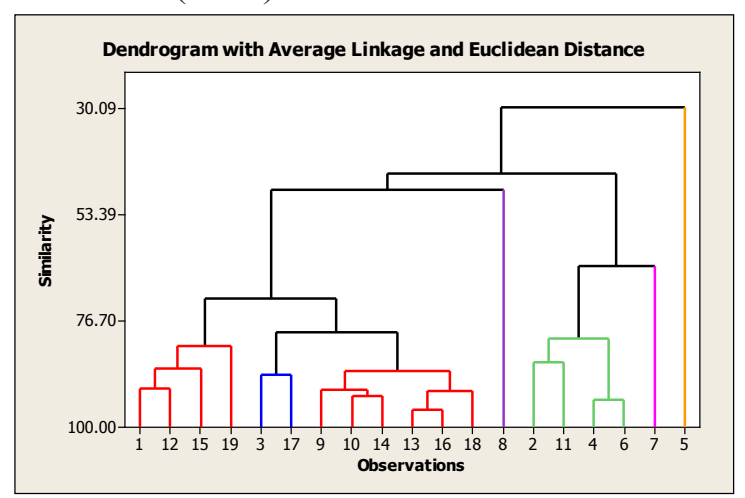

Fig.2: A dendrogram showing clusters of 19 different landraces of rice

\section{Principle component analysis:}

According to principle components among 19 landraces of rice, in PCI, highest loaded value is that of panicle length, in PCII highest loaded value was that of ligule length, in PCIII grain width had the highest loaded value and in PCIV grain length had highest loaded value. The highest value shows that it contributes the most in the variability in each Principal component. In PCI panicle length, days to heading, leaf length, culm length were the most important characters contributing to the variability. In PCII, the important characters are ligule length, leaf length, 100 grain weight, grain length were important characters contributing to the variability. Similarly, culm number, grain width, 100 grain weight, days to heading was important characteristics contributing to the variability. However, in PCIV, grain length, leaf width, 100 grain weight, and grain width were the important characteristics contributing to the variability. For the first principal component panicle length, days to heading, leaf lengths were the most important characters. Results of this study can be helpful in identifying landraces with similar traits which can be helpful to identify accessions within landraces with similar traits which can be useful for sampling and subsequent studies and parental selection in the breeding program.

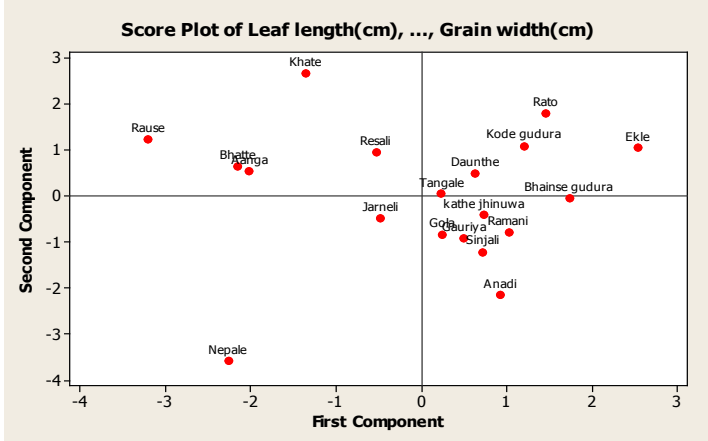

Fig.3: Plotting Principal components, first and second, grouped the landraces based on their similarity level. 
It shows that Khate, Rause, Bhatte, Aanga, Resali within the second quadrant are closely related to each other. So, if we want to use the landraces from this group, we can use any one of these in varietal improvement. Similarly, in the first, third and fourth. Nepale landraces seem to be farthest from the rest which has special characters in relation to others.

Score plot of quantitative characteristics showed four principal component groups. PC I containsKhate, Rause, Bhatte, Aanga and Resali. PC II contains Jarneli and Nepale. PC III contains KhateJhinuwa, Ramani, Gola, Gauriya, Sinjali and Anadi. PC IV contains Rato, Kodegudura, Ekle, Dauthe, Tangale and Bhainsegudura.

\section{CONCLUSIONS}

This study carried out for agro-morphological diversity among different landraces revealed the following salient features: There were about 19 landraces of rice cultivated in the VDC for a long before. There were ten quantitative characters among the characters provided by the IPGRI descriptor. Cluster analysis of quantitative characteristics grouped the rice landraces into 4 clusters with a dendrogram. The principal component analysis revealed all rice landraces into four groups (according to a multivariate analysis using MINITAB 14). These rice landraces with different genotypes can be exploited for germplasm conservation and breeding purposes. The most varied genotypes may yield a good variety for such an area. Tangale landrace was found to be cultivated in the study area and peripheral VDCs from a long time ago and known by Balewaligudura.

\section{ACKNOWLEDGEMENTS}

I am thankful to the Nepal Academy of Science and Technology (NAST) for providing fund for this research work. I am indebted to immediate supervisor Prof. Dr CB Thapa, PN Campus, Tribhuban University. I am thankful to agronomist Dr Ramesh Raj Puri for cluster analysis and PCA.

\section{REFERENCES}

Annonymous, (2011). Bioversity International, Rome, (Italy); International Rice Research Institute, Los Baños, (Filipinas); AfricaRice, Centro de Arroz da Africa, Cotonou, (Benin).

Adhikari N.P., M.M. Palikhe, and RN Devkota (1994). Status of Rice, Maize and Wheat genetic resources in Nepal. In: Plant genetic resources in Napelese perspectives, NARC and IPGRI. Upadhyaya, Saiju, Baniya and Bista (ed).

CBS, (2013). Village Development Committee Statistics, Central Bureau of Statistics, Nepal.

Chaudhary R.P., (1984). Vegetation Pattern In: Nepal Nature's Paradise, 105-111p, Majupuria, TC (ed) White Lotus Company Ltd, Bangkok, Thailand (Pub).

Mau Y.S., J.E.R. Markus, S. Oematan, A.S.S. Ndiwa, D.D. Handoko, A. Nasution, K. Makbul (2017). Genetic diversity of red and black upland rice accessions from East Nusa Tenggara, Indonesia as revealed by agromorphological characters. Biodiversitas 18 : 197-211

Nascimento W.F., E.F. Silva, Ann Elizabeth and E.A. Veasey (2011). Agro-morphological characterization of upland rice accessions, Sci. agric. (Piracicaba, Braz.), 68 (6). http://dx.doi.org/10.1590/S010390162011000600008

Pathak H.N. and G.P. Poudyal (2008). Inventory on ethnobotanical knowledge on Oryza sativa L cultivated in Paiyunpata VDC Baglung. A research report submitted to the research committee, Prithvi Narayan 
Campus, Pokhara, Nepal.

Roy S.C. and B.D. Sharma (2014). Assessment of genetic diversity in rice [Oryza sativa L.] germplasm based on agro-morphology traits and zinc-iron content for crop improvement. Physiology and Molecular Biology of Plants, 20(2), 209-224. doi:10.1007/s12298-014$0221-y$.

Yadav R.B., P. Chaudhari, J. Bajracharya., D.K. Rijal, S.P. Khatiwada., R.K. Tiwari, R.K. Yadhav, M.P. Upadhyaya, A. Mudwari, B.K. Baniya, S.K. Gupta, A.K. Gautam, and B.K. Joshi (2001). Agro-morphological diversity in rice landraces of Bara and Kaski ecosites. In: On farm management of agricultural biodiversity Nepal. Proceedings of National Workshop, 24-26 April. B.R. Sthapit, M.P. Upadhyaya, B.K. Baniya and B.K. Joshi (ed).

Received 17 May 2018

Revised accepted 25 September 2018 